\title{
Hotdogs at the end of the world
}

\section{So long, and thanks for all the sausages.}

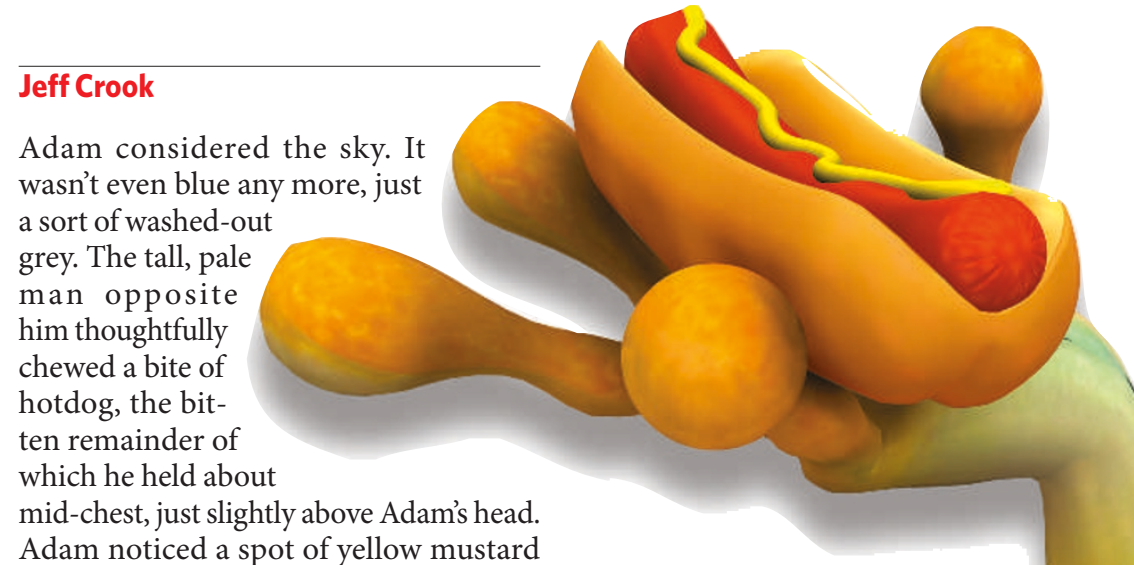

Adam noticed a spot of yellow mustard on the man's red tie. His suit was black, as were the sunglasses resting on top of his wavy blond hair. His almost-colourless blue eyes remained fixed in an unblinking stare that Adam still found somewhat unsettling.

"What you say is true," Adam continued, "but the conflict between theology and interstellar travel isn't just with the book of Genesis. There's Revelations to consider. Of course, Norse mythology also includes an end-times myth, Ragnarok and all that, but there are so few Odin-worshippers these days, it seems pointless to include them."

"Entirely," the Nordic-looking man mumbled around his hotdog.

"Uh... entirely what?" Adam asked.

"Pointless," the man said. Adam noticed that the spot of yellow mustard had disappeared from the man's tie.

"Wonderful technology," Adam muttered before continuing. "But as you know, UFO researchers always assumed that the government actively concealed the existence of extraterrestrials to protect the Church, referring of course to the question raised by Genesis - if there are extraterrestrial civilizations, why aren't they mentioned in Genesis? The Brookings Institute is supposed to have done the original sociological study that has guided disclosure policy since the middle of the last century."

"That's true," the Nordic man said.

"It is? Oh, yes, but in my opinion the answer to the Genesis question wouldn't bring down the Church, would it? One could always argue that Genesis never says aliens don't exist, either."

"Obviously," the Nordic man said. He finished his hotdog. Adam removed another one from the grill, bunned it, squirted a line of mustard down its pink and char-blackened length, and handed it over the grill to his guest.
"Obviously. So

the real sticking point is Revelations," Adam said. "Do you want a beer or something?"

"Yes," the Nordic man said. Adam opened a longneck using the bottleopener feature on his grill spatula. A shadow of a smile twitched the corners of the tall man's narrow mouth. "That's a useful device," he said as Adam handed him the beer.

"So, as I was saying, Revelations and all the other Armageddon philosophies," Adam continued. "I mean, if there are other worlds out there where a man... being... whatever... can be born, live and die without ever setting foot on Earth, that kind of pulls the end-timers' teeth, doesn't it? Without an end-times in which sinners are judged and the righteous rewarded, Western religion becomes rather pointless. God destroys the world - big deal. Sure, a few billion people die, but in the big picture, it's a minor occurrence. Planets explode every day, am I right? Whole star systems go nova, trillions of intelligent life forms wiped out in the twinkling of an eye, no matter how moral or immoral they are or were. It's physics, and a lack of sufficiently advanced technology to detect the impending Armageddon and/or to escape it by fleeing their doomed planet."

The Nordic man ate his hotdog and drank his beer without blinking. Adam noticed that the man's bottom lip (which was somewhat fuller than his almost-fleshless upper lip) tended to get sucked into the neck of the bottle when he drank, making a comical squeaking noise when he pulled it out.

Adam glanced at the cloudless grey sky, his voice rising as he tried not to laugh. "And since these end-times religions selfperpetuate by exerting control over their congregants by holding or withholding the metaphysical keys to heaven, take away the end times and what are they left with?"

"Where do you purchase these?" the Nordic man asked, gesturing with his beer to the half-eaten hotdog in his hand.

"I make them myself. Secret family recipe," Adam said. "The beef is Kosher."

"They are delicious," the tall man said. "I'll mention them to the Minister of Culture."

Adam smiled. He felt his point had been made. The back door opened and a small, light-grey alien stepped outside. "Thanks, Adam," the alien said with obvious relief. "I was about to bust."

"Not a problem, Thraz. Did you remember to flush?" Adam asked.

"Oh. Sorry." The alien blushed a deeper shade of grey and glanced at the Nordic man, who was still examining the uneaten remainder of his hotdog.

"Don't worry. I'll get it," Adam said. "Your pee dissolved the toilet last time. Try explaining that to the plumber. You want another beer or something?"

"Thanks, no. I'm driving. Well, see you later," the small alien said. He climbed into the metallic-green, lozenge-shaped spacecraft parked in Adam's backyard. The Nordic man ate the last half of his hotdog in one bite, set the empty beer bottle on a fencepost, and climbed into the spacecraft without so much as saying goodbye. Adam was used to this. The tall ones seemed unemotional, but the little guys were friendly enough.

Adam waved goodbye as the door materialized and blended seamlessly with the hull of the ship. The craft rose silently to treetop level, then shot off towards the encroaching sea, leaving behind a rainbow arc that shimmered in the washed-out sky for a second or two before fading. Adam smiled and popped an olive into his mouth as the sound of waves reached his ears.

High tide again, and getting closer every day. So much for that covenant.

Yes, interstellar travel is a lovely way to escape the end of the world and all its moral obligations, Adam thought with a rising sense of hope and purpose.

Jeff Crook, father of two, husband of one, author of many, publisher of few, editor, too, is halfway to the end of his squib: (n) - a noisemaker or failed magician. 